\title{
Influence of Long Polypropylene Fibre on the Properties of Concrete
}

\author{
Ashfaque Ahmed Jhatial ${ }^{1,}{ }^{*}$, Aamir Khan Mastoi ${ }^{2}$, Zafar Ali Siyal ${ }^{3}$, Touqeer Ali Rind ${ }^{1}$, Imtiaz Ahmed \\ Memon ${ }^{4}$ \\ ${ }^{1}$ Department of Civil Engineering, MUET, Shaheed Zulfiqar Ali Bhutto Campus, Khairpur Mirs', Sindh, Pakistan. \\ ${ }^{2}$ Department of Civil Engineering, QUEST, Nawabshah, Sindh, Pakistan \\ ${ }^{3}$ Department of Energy and Environment Engineering, QUEST, Nawabshah, Sindh, Pakistan. \\ ${ }^{4}$ Department of Civil Engineering, MUET, Jamshoro, Sindh, Pakistan. \\ ${ }^{*}$ Corresponding author: ashfaqueahmed@muetkhp.edu.pk
}

\section{Abstract}

Concrete is the most used building and construction material globally due to the ease of availability and durability. It is a well-known fact that concrete can easily withstand compressive stresses; however, it fails under tension. To improve this deficiency, steel bar reinforcement has been used. However, with the steel reinforcement, additional permanent self-weight is transferred on the structure and is prone to corrosion. Hence, engineers and researchers have been working to search for more sustainable reinforcing material that could be cost-effective and simultaneously increase tensile strength. This experimental work was carried out to study the influence of long $(38.1 \mathrm{~mm})$ polypropylene (PP) fibres on the workability and mechanical strengths (compressive and flexural) of concrete. Three different fibre fraction content, $0.20 \%, 0.25 \%$ and $0.30 \%$ were selected to reinforce concrete. A total of 12 cylinders of $300 \mathrm{~mm} \times 150 \mathrm{~mm}$ dimension ( 3 cylinders per mix) and 12 beams of $609.6 \mathrm{~mm} \times 304.8 \mathrm{~mm} \times 101.6 \mathrm{~mm}$ dimension ( 3 beams per mix) were used to determine the compressive strength and flexural strength after the samples achieved 28 days curing. Based on the results, it can be observed that longer fibres do not significantly influence the compressive strength as much as they do on flexural strength. Furthermore, longer length fibres, like shorter fibres, obstruct the workability of concrete. Comparing with previous findings, it can be concluded that for patching of macrocracks, longer length PP fibres should be used.

Keywords-Compressive Strength, Fibre Reinforced Concrete, Flexural Strength, Polypropylene Fibres, Workability

\section{Introduction}

$\mathrm{C}$ oncrete is one of the best inventions of human $\checkmark$ being and is the second most-consumed substance in the world, just after water. The availability, durability and flexibility have made concrete the most preferred building and construction material in the world [1][2]. It is being used in vast civil engineering applications ranging from the construction of residential houses to high rise buildings, bridges to dams, airports to nuclear plants, etc. [3]. However, since its invention, concrete has been known to be robust under compressive loading while relatively weak under tension. To overcome this weakness of concrete, researchers and engineers tried to transform the brittle behaviour of concrete into ductile and improve

ISSN: 2523-0379 (Online), ISSN: 1605-8607 (Print)

DOI: 10.52584/QRJ.1802.06

This is an open access article published by Quaid-e-Awam University of Engineering Science \& Technology, Nawabshah, Pakistan under CC BY 4.0 International License. the tension deficiency with the help of reinforcement steel bars. Although the Reinforced Cement Concrete (RCC) with steel bars has changed the behaviour of concrete while enhancing the mechanical properties of concrete, the reinforcing of concrete with steel bars does come at a price. The self-weight of concrete itself is high due to the higher density of normal weight concrete. Still, this self-weight with the reinforcement steel bars exponentially increases, causing increased permanent load on the structures. The steel bars are prone to corrosion; once the corrosion occurs, concrete can be severely damaged from within [4]. Reinforcing concrete with more sustainable material than steel bars has become essential.

Researchers have focused on the utilization of different types of Fibres to Reinforce Concrete (FRC). With the exception of fibres, the FRC is the same type as conventional concrete. FRC consists of hundreds of small fibres uniformly scattered and distributed evenly 
in concrete during mixing. The key characteristics of fibre reinforcement, making it more appealing than the steel bar include the following.

1) The utilization of steel reinforcement is more or less depending upon where it is necessarily required, whereas, the fibres can be spread along the cross-section.

2) Unlike steel bars, which are continuous and relatively spaced, the fibres which could be used as reinforcement material differ in length, despite the variation, the fibres are still shorter and widely spaced than steel bars.

3) The same fibre reinforcement area as steel bars is usually not feasible.

4) The FRC is more hardened and impact-resistant than ordinary concrete.

The primary purpose of FRC is not just to enhance the strength, but to change the concrete's behaviour. With the addition of fibres, concrete can change from brittle to ductile, as shown in Figure 1. This behavioural improvement is accomplished by bridging these cracks, supplying the concrete with some post-cracking ductility. In addition to the behavioural change, the fibres enhance other properties such as control cracks, increase the tensile, flexural and fracture strengths, durability and impact resistance, etc. [5][6]. FRC efficiency depends on the fibre type used. Over the years, various types of fibres have been manufactured worldwide, and these fibres range from synthetically organic (polypropylene fibres) and inorganic (steel or glass), natural organic (cellulose or sisal) to inorganic (asbestos) [7]. Concrete mix design is not needed when using these fibres in concrete. Among the fibres used in FRC, hydrophobic polypropylene (PP) fibres do not absorb water, making it a revolutionary fibre that can improve tensile and flexural capabilities, resilience and resist cracking. This experimental study focuses on the influence of long $(38.1 \mathrm{~mm}) \mathrm{PP}$ fibres when used at $0.20 \%, 0.25 \%$ and $0.30 \%$ fibre fraction content on the workability, the compressive and flexural strength of concrete.

\section{Related Work}

Most of the buildings are constructed of concrete and steel, known as RCC structures. Steel bars are used as reinforcement to overcome the tensile deficiency of con-rete. However, steel bar reinforcement has a significant disadvantage, one being easily corroded and additional self-weight in the form of permanent load. Furthermore, the addition of steel bars increases the cost of structures and require continuous repair and maintenance is also needed to increase the life span of

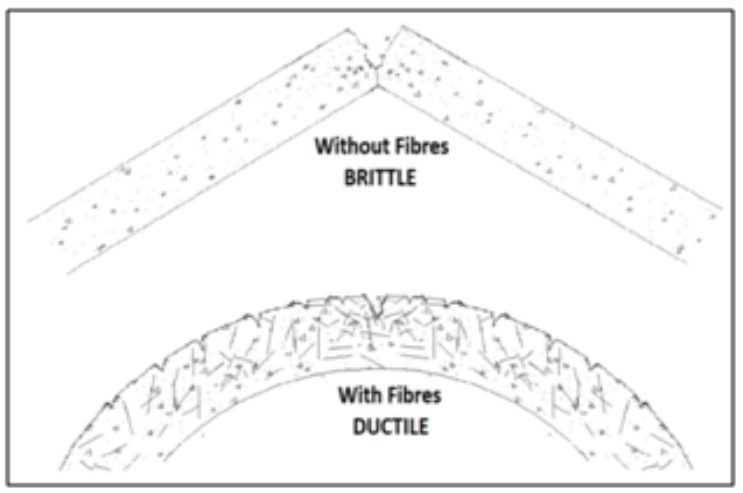

Fig. 1: Change in Behaviour of Concrete Due to Fibres Reinforcement [4].

structures. Different methods or strategies are used in building to eliminate civil structure failure [8]. Various fibres are used as reinforcement in concrete to mitigate cracks. This fibre-adding technique increases tensile strength, resilience, cracking and deformation of civil engineering structures. But a drawback of this technique becomes apparant when these composites are exposed to some marine environment. Due to surface blistering, adhesive bond strength decreases, resulting into de-lamination [8].

Jhatial et. al. [9] used steel fibres to reinforce concrete, and it was found that with reinforcing concrete with the steel fibres, the workability decreased significantly. The higher the steel fibre content, the lower the workability. However, despite the reduced workability, it was reported that steel fibres improved the ductility behaviour of concrete and achieved $18.57 \%$ and $51.72 \%$ increase in compressive and flexural strengths, respectively. It was found that $3 \%$ fibre content was optimum. These findings were confirmed by Ali et. al. [10].

Apart from steel fibres, plastic fibres were used to reinforce concrete, Lakhiar et. al. [11] and Keerio et. al. [12] used $0 \%$ to $1 \%$ plastic fibres with an increment of $0.2 \%$ as reinforcement material and studied the flexural strength of the concrete. It was found that the workability of concrete slightly reduced with the addition of plastic fibres, which was attributed to the fibres' resistance to flow. The flexural strength showed an increase of up to $16.5 \%$ and the optimum plastic fibre content was found to be $0.6 \%$.

Despite the vast number of fibres that could be used in FRC production, PP fibres stand out as the most liable and preferred fibres to use as a reinforcement material. Polypropylene is a polymerized propylene, a by-product of petroleum refining [13]. The utilization of PP fibres as a reinforcement material 


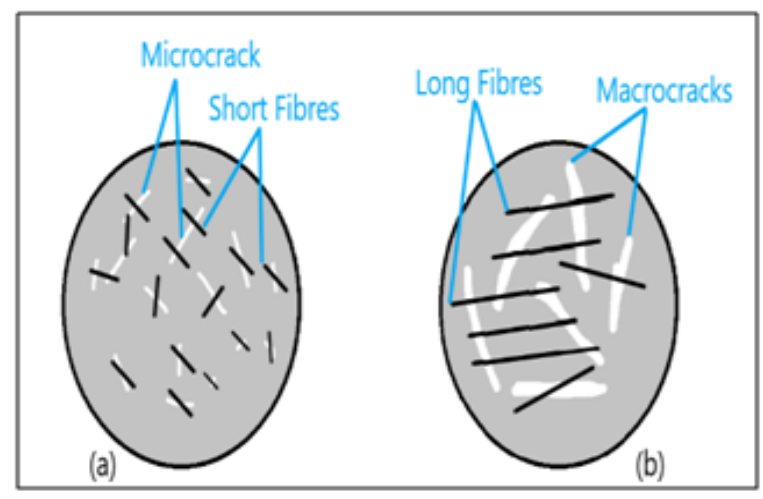

Fig. 2: Influence of (a) short fibres and (b) long fibres on the on micro-cracks and macrocracks, respectively

in concrete helps in withstanding tensile stresses, by developing a bridge in the concrete matrix, which controls the cracks' propagation. Due to these properties, PP fibres have been added over the years in different concrete forms, ranging from standard traditional concrete to lightweight foamed concrete.

Memon et. al. [4] reinforced concrete with two different PP fibre lengths $(12.7 \mathrm{~mm}$ and $25.4 \mathrm{~mm})$ and three different contents $(0.20 \%, 0.25 \%$ and $0.30 \%)$. It was found that fibre length had a significant influence on the properties of concrete. Furthermore, it was reported that short length fibres achieved higher compressive strength with the gradual increase in fibre content but lower flexural strength. In contrast, a reduced compressive strength was achieved with longer length fibres; however, the flexural strength was still higher than the control sample. This behaviour was attributed to the merging of micro-cracks to become macro-cracks when the load is increased. Shorter length fibres are not able to cover macro-cracks, thus are ineffective. The shorter length PP fibres are more useful only when there are micro-cracks, as shown in Figure 2. Foamed concrete, being of lower density, is more prone to cracking; therefore, Jhatial et. al. [14] investigated the impact on the mechanical properties of foamed concrete with PP fibres' addition. It was reported that the addition of PP fibres enhanced the mechanical strength of foamed concrete. It was found that using $0.15 \%$ PP fibres produced the highest increase in mechanical properties. Interestingly, the addition of PP fibres in foamed concrete improved the thermal properties [13]15] by reducing the thermal conductivity value of foamed concrete. This was attributed to the hydrophobic nature of PP fibres. However, previous research [4][13][14][15] on the PP fibres have utilized shorter or medium size (12.7 to 25.4 $\mathrm{mm}$ ) fibres, and there is a lack of understanding on the

\begin{tabular}{|l|l|}
\hline Property & Value \\
\hline Length $(\mathrm{mm})$ & 38.1 \\
\hline Specific Gravity & $0.90-0.91$ \\
\hline Reaction with water & Hydrophobic \\
\hline Tensile strength at break (psi) & $4500-6000$ \\
\hline Elongation at break (\%) & $100-600$ \\
\hline Water absorption (\%) & $0.01-0.03$ \\
\hline
\end{tabular}

TABLE 1: Properties of polypropylene fibers

influence of even longer PP fibres on the properties of concrete.

\section{Methodology}

To study the influence of longer PP fibres, plain cement concrete was prepared. Attock cement was used, which is CEM 1, class $42.5 \mathrm{~N}$ and adheres to EN 1971:2011 [16]. The fine aggregates which were obtained from Bolhari quarry were sieved through $4.75 \mathrm{~mm}$, and coarse aggregates obtained from Petaro crushing plant was sieved through $20 \mathrm{~mm}$ and oven-dried to remove the excess moisture, and then kept in air-tight plastic bags till casting. An M20 grade, concrete was prepared using 1:2:4 ratio, and the water-cement ratio of 0.50. Furthermore, $38.1 \mathrm{~mm}$ long PP fibre (Fig. 3a) was used to reinforce the concrete at $0.20 \%, 0.25 \%$ and $0.30 \%$ fibre fraction volume. The properties of PP fibres are shown in Table 1. The raw materials, which include the ordinary Port-land cement and aggregates, were placed in the concrete mixer and allowed to mix and the water was gradually added. Afterwards, the PP fibres were thrown into the mix slowly to ensure uniform distribution of PP fibres throughout the mix. The workability of the concrete reinforced with PP fibres was determined using slump loss. Afterwards, the mixture was poured into the mould, which was kept in the open air for 24 hours before being demoulded and placed in the water tank for 28 days.

After proper water curing, the cylindrical samples of $300 \mathrm{~mm} \times 150 \mathrm{~mm}$ dimension, were taken out of the water tank, and tested for compressive strength, as shown in Figure 3b, according to BS EN 12390-3:2019 [17]. The beam specimens of $609.6 \mathrm{~mm} \times 304.8 \mathrm{~mm} \times$ $101.6 \mathrm{~mm}$, as shown in Figure 3c, were tested for flexural strength, according to BS EN 12390-5:2019 [18].

\section{Results \& Discussion}

\subsection{Workability}

The workability of concrete mixes was recorded using a slump cone as per the specifications set in ASTM C143 [19], and is illustrated in Figure 4. It can be seen 


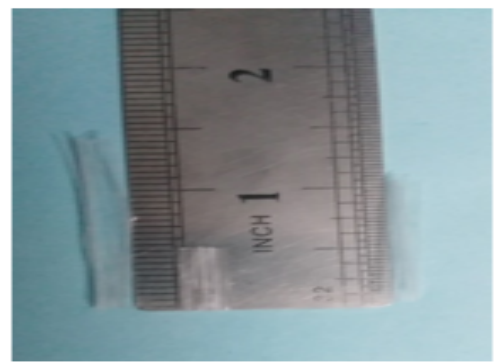

(a) $38.1 \mathrm{~mm}$ polypropylene fibres

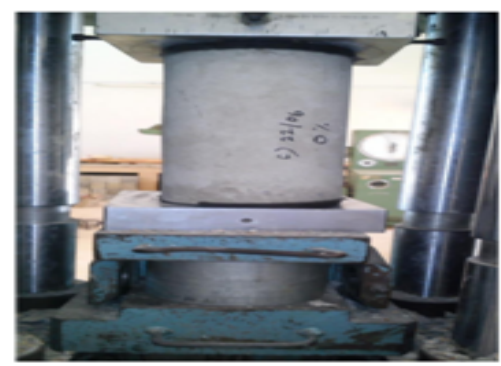

(b) compressive strength test setup

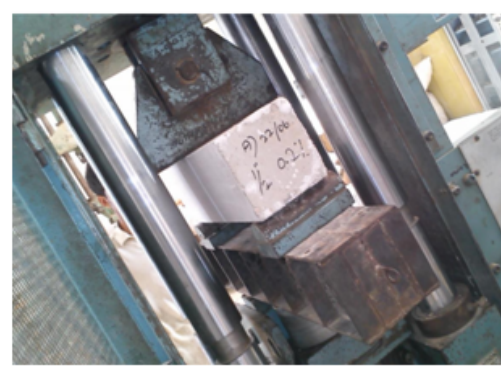

(c) Flexural strength test setup

Fig. 3: Illustration of compressive strength

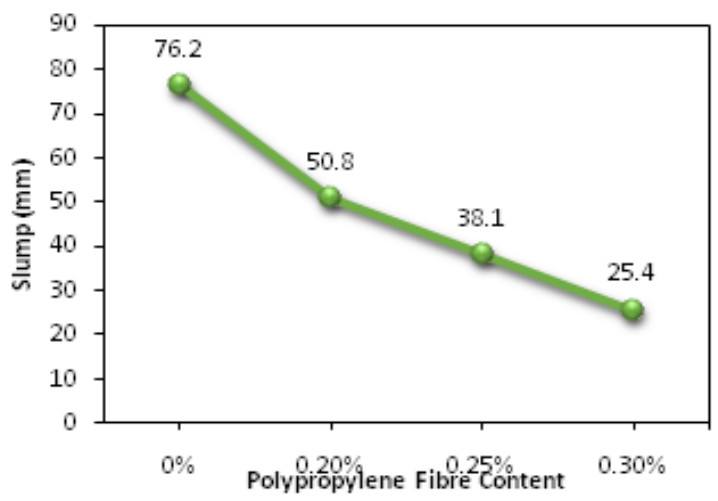

Fig. 4: Influence of $38.1 \mathrm{~mm}$ long PP fibre on the workability of concrete

that with the addition of PP fibres, the workability is severely affected. This can be attributed to the longer length of PP fibres, which cause hindrance. The higher fibre content the further reduction in workability is obtained.

\subsection{Compressive Strength}

Table 2 and Figure 5 depict the average compressive strength of concrete and the influence of $38.1 \mathrm{~mm}$ long PP fibres. It can be observed that the concrete (M1) with 0\% PP fibres, achieved 22.46 MPa. With the addition of $0.20 \%$ PP fibres (M2), the compressive strength increased up to $7.84 \%$ compared to the M1 sample. However, a further increase in PP fibre content reduced the compressive strength than the control (M1) samples. The similar trend was reported by Memon et. al. [4] and Phulpoto et. al. [20] who compared shorter length $(12.7 \mathrm{~mm})$ andmid-length $(25.4 \mathrm{~mm})$ PP fibres. This could be attributed to the fact that longer PP fibres cause an increase in permeability in concrete; therefore, higher the fibre content, the increase in permeability which directly influences the compressive strength of concrete.

\begin{tabular}{|l|l|l|l|}
\hline Mix & $\begin{array}{l}\text { PP Fibre } \\
\text { Content }\end{array}$ & $\begin{array}{l}\text { Compressive } \\
\text { Strength } \\
\text { (MPa) }\end{array}$ & $\begin{array}{l}\text { Difference } \\
\text { w.r.t. to M1 } \\
\text { (\%) }\end{array}$ \\
\hline M1 & $0 \%$ & 22.46 & - \\
\hline M2 & $0.20 \%$ & 24.22 & +7.84 \\
\hline M3 & $0.25 \%$ & 20.62 & -8.19 \\
\hline M4 & $0.30 \%$ & 21.14 & -5.88 \\
\hline
\end{tabular}

TABLE 2: Compressive strength of concrete

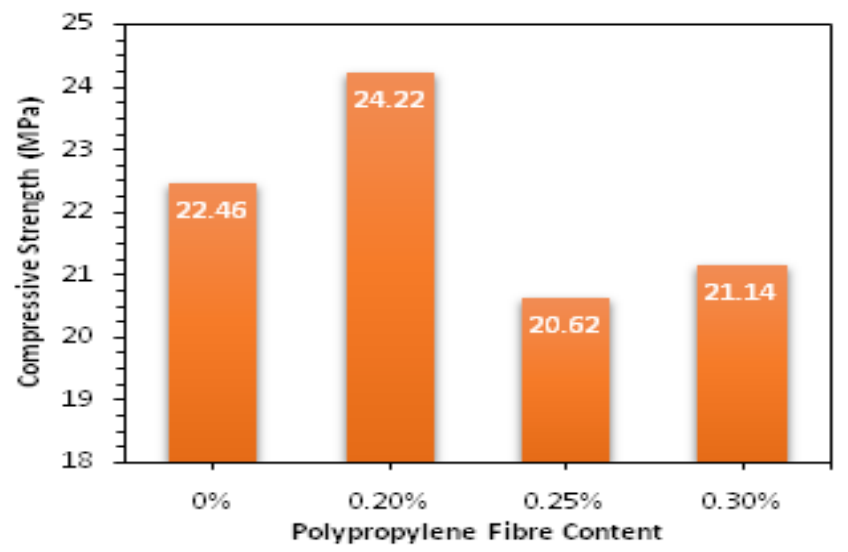

Fig. 5: Influence of $38.1 \mathrm{~mm}$ long PP fibre and fibre content on the compressive strength of concrete

\subsection{Flexural Strength}

The Table 3 and Figure 6 present the flexural strength of concreteand influence of $38.1 \mathrm{~mm}$ long PP fibres. It can be observed that an increase in PP fibres causes a significant increase in the flexural strength of concrete. In contrast to the behaviour observed during the compressive strength testing, the M3 and M4 samples with $0.25 \%$ and $0.30 \%$ PP fibres exhibited higher flexural strength than the control sample M1. Similar behaviour was also reported by [4]. In the interfacial zone, the micro-cracks are initially developed when the concrete is subjected to tensile stresses. With the gradual increase in the tensile stress, these small random micro-cracks propagate and merge into larger 


\begin{tabular}{|l|l|l|l|}
\hline Mix & $\begin{array}{l}\text { PP Fibre } \\
\text { Content }\end{array}$ & $\begin{array}{l}\text { Compressive } \\
\text { Strength } \\
\text { (MPa) }\end{array}$ & $\begin{array}{l}\text { Difference } \\
\text { w.r.t. to M1 } \\
\text { (\%) }\end{array}$ \\
\hline M1 & $0 \%$ & 3.83 & - \\
\hline M2 & $0.20 \%$ & 3.79 & -1.04 \\
\hline M3 & $0.25 \%$ & 4.38 & +14.36 \\
\hline M4 & $0.30 \%$ & 3.92 & +2.35 \\
\hline
\end{tabular}

TABLE 3: Flexural strength of concrete

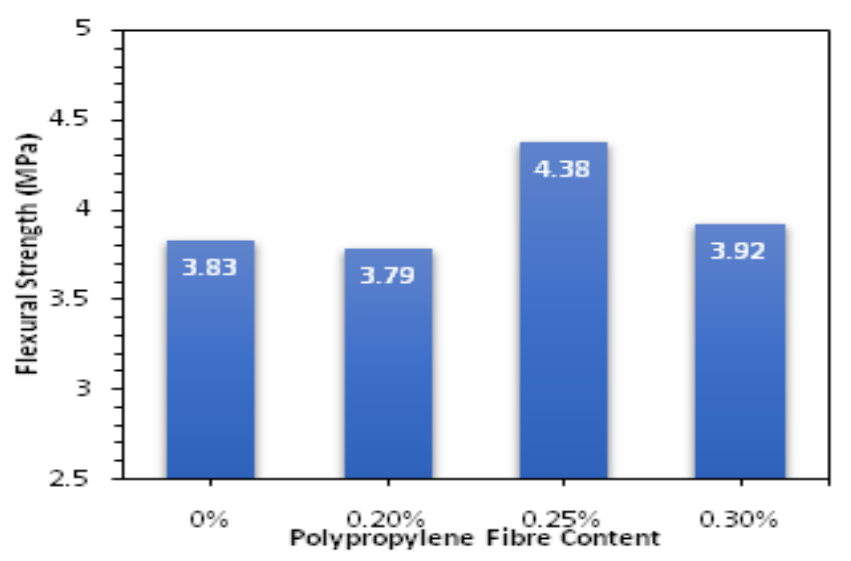

Fig. 6: Influence of $38.1 \mathrm{~mm}$ long PP fibre and fibre content on the flexural strength of concrete

cracks (macrocracks), and ultimately end up causing the concrete to fail.

As reported by Memon et. al. [4], shorter PP fibres help bridge smaller micro-cracks, as shorter PP fibres occupy smaller space than longer PP fibres. Thus, at the same volume, the number of shorter PP fibres are more significant in number, and therefore, patch up more micro-cracks more effectively. If the micro-cracks and lower stress are the consideration parameters, then the short fibres exhibit significant crack bridging also enhance the tensile strength of concrete. Previous studies [21][22] have suggested that the PP fibre reinforcement of concrete prevents the development and propagation of micro-cracks, while reducing the overall sizes of micro-cracks by preventing the micro-cracks from bridging with each other, and not causing microcracks to grow any bigger. However, with the gradual increase in stress, the micro-cracks merge together to form larger macro-cracks, which cannot be controlled or bridged with shorter length PP fibres. Longer PP fibres have shown that they are better in bridging macro-cracks and therefore the behaviour of concrete was being enhanced and the stiffness was being increased. PP fibre bridging mechanism improves tensile and flexural capacities. Short and long fibres are shown in Figure 2.

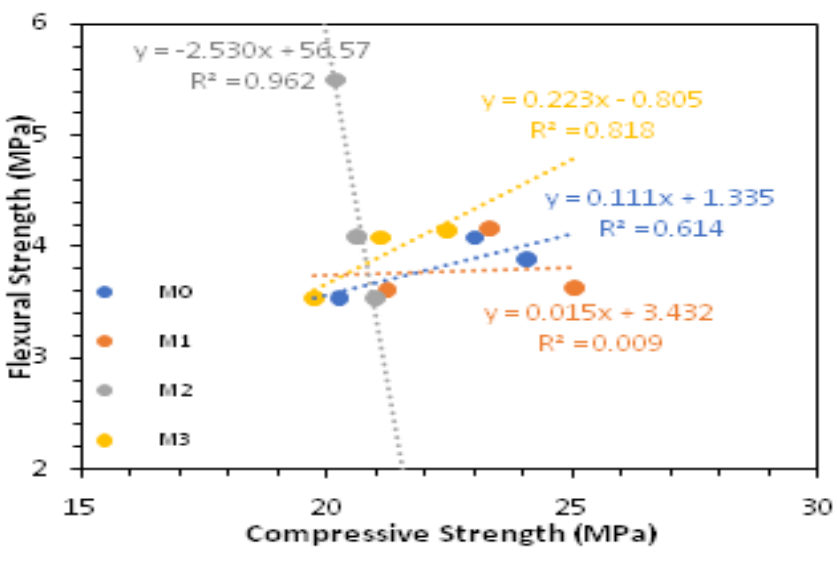

Fig. 7: Compressive-flexural strength relationship of concrete reinforced with PP fibres

\subsection{Compressive-Flexural Correlation}

A linear relationship was developed through statistical procedures to assess the determined compressive and flexural strength behaviour of concrete reinforced with different PP fibre content at the age of 28 days. R2 value, determined through regression curve analysis, was considered as the relationship coefficient in this experimental work [23][24]. The regression curve line shows the relationship between the independent variable (compressive strength) and the dependent variable (flexural strength) in the graph, as shown in Figure 7 . The developed equation, along with the R2 coefficients, is as follows.

$$
\begin{array}{cc}
f_{r_{M 0}}=0.1111 * f_{c u_{M} 0}+1.335 & R^{2}=0.6146 \\
f_{r_{M 1}}=0.0155 * f_{c u_{M} 1}+3.4321 & R^{2}=0.0091 \\
f_{r_{M 2}}=-2.5308 * f_{c u_{M} 2}+56.575 & R^{2}=0.9621 \\
f_{r_{M 3}}=0.2235 * f_{c u_{M} 3}-0.8055 & R^{2}=0.8182
\end{array}
$$

Where: $f_{r_{M x}}$ is flexural strength of $M x(M 0, M 1, M 2$ and M3) mix in MPa, $f_{c u_{M} x}$ is the compressive strength of $M x(M 0, M 1, M 2$ and $M 3)$ mix in $\mathrm{MPa}$, and $R^{2}$ is regression coefficient.

A general rule of thumb may be used to interpret the correlation between the two variables based upon the obtained $R 2$ as follows.

1) $R^{2}< \pm 0.25 \rightarrow$ no relation

2) $\pm 0.25<R^{2}< \pm 0.50 \rightarrow$ weak relation

3) $\pm 0.50<R^{2}< \pm 0.75 \rightarrow$ moderate relation

4) $R^{2}> \pm 0.75 \rightarrow$ strong relation

Based upon this general thumb rule, it can be concluded that compressive and flexural strengths of concrete without any PP fibres of are of moderate relation. While with $0.20 \%$ PP fibres, no relation exists. Furthermore, the addition of $0.25 \%$ and $0.30 \%$ PP fibres have very strong relationship. 


\section{Conclusion}

This study is aimed to determine the influence of longer length polypropylene fibres on the workability and mechanical strength (in terms of compressive and flexural) of concrete. Based on the results, the following conclusions can be drawn:

- The long PP fibres due to extended length obstruct the workability of concrete.

- Upon gradual increase in stresses, microcracks merge and become macrocracks. Shorter length PP fibres can only patch microcracks, whereas longer length PP fibres are better suited to bridge macrocracks.

- Longer PP fibres may not enhance the compressive strength in the same way as flexural strength. Considering concrete is weaker in tension, the optimum PP fibre content was found to be $0.25 \%$.

- The length of fibre influences not only the freshstate properties of concrete, but also hardenedstate properties.

\section{Acknowledgement}

The authors would like to acknowledge the support received from the Department of Civil Engineering, Mehran University of Engineering and Technology, Jamshoro and Shaheed Zulfiqar Ali Bhutto Campus, Khairpur Mirs, Sindh, Pakistan.

\section{References}

[1] Jhatial, A. A., Goh, W. I., Rind, T. A. and $\mathrm{Ku}-$ mar, A.,"Thermal Performance Simulation of EcoFriendly Lightweight Foamed Concrete Incorporating Palm Oil Fuel ash and Eggshell Powder Using ABAQUS",Silicon, pp.1 21, 2021.

[2] Raza, M. S., Rai, K., Kumar, D. and Ali, M.,"Experimental Study of Physical, Fresh-State and Strength Parameters of Concrete incorporating Wood Waste Ash as a Cementitious Material",Journal of Materials and Engineering Structures, vol. 7, no. 2, pp. 267-276, 2020.

[3] Mahmood, K.,"Factors Affecting Reinforced Concrete Construction Quality in Pakistan", In CBM-CI International Workshop, pp. 374-380, 2007.

[4] Memon, I. A., Jhatial, A. A., Sohu, S., Lakhiar, M. T. and Hussain, Z., "Influence of fibre length on the behaviour of polypropylene fibre reinforced cement concrete", Civil Engineering Journal, vol. 4, no. 9, pp. 2124-2131, 2018.

[5] Madhavi, T.C., Raju, L.S. and Mathur, D.,"Polypropylene fibre reinforced concrete - a review", International Journal of Emerging Technology and Advanced Engineering, vol. 4, issue no. 4, pp. $114-119,2014$.

[6] Manjunatha, J.K., Sanjith, J., Ashwini, B.T. and Ranjith, A.,"Fibre Reinforced Self Compacting Concrete - A Review", International Journal of Science, Technology \& Management, vol. 04, no. 02, pp. 120 - 124, 2015.

[7] Brown, R., Shukla, A. and Natarajan, K.R., "Fibre reinforcement of concrete structures", (No. URITC FY99-02,) Kingston: University of Rhode Island Transportation Center, 2002.
[8] Nair, M.M., Shetty, N., Alva,P. P.and Shetty, S.D.,"Effect of sawdust impregnation on long coir fibres reinforced with epoxy matrix", International Journal of Advanced and Applied Sciences, vol. 5, no. 3, pp. $67-74,2018$. DOI: 10.21833/ijaas.2018.03.010

[9] Jhatial, A. A., Sohu, S., Bhatti, N. K., Lakhiar, M. T. and Oad, R.,"Effect of steel fibres on the compressive and flexural strength of concrete", International Journal of Advanced and Applied Sciences, vol. 5, no. 10, pp. $16-21,2018$.

[10] Ali, S., et. al., "Effects of steel fibres on fresh and hardened properties of cement concrete", Civil and Environmental Engineering Reports, vol. 30, no. 3, pp. 186 - 199, 2020.

[11] Lakhiar, M. T., et. al., "Flexural Performance of Concrete Reinforced by Plastic Fibers", Engineering, Technology \& Applied Science Research, vol. 8, no. 3, pp. 3041 - 3043, 2018.

[12] Keerio, M. A., Lakhiar, M. T. and Sohu, S., "Comparative Study on Flexural Performance of Foamed Concrete Beam Containing Plastic Fibres", International Journal of Sustainable Construction Engineering and Technology, vol. 10, no. 1, pp. $1-8,2019$.

[13] Jhatial A.A., Goh W.I., Mohamad N., Alengaram U.J.and Mo K.H., "Effect of Polypropylene Fibres on the Thermal Conductivity of Lightweight Foamed Concrete", MATEC Web of Conferences 150, pp. 1 - 6, 2018.

[14] Jhatial, A. A., Goh, W. I., Mohamad, N., Hong, L. W., Lakhiar, M. T., Samad, A. A. A. and Abdullah, R.,"The Mechanical Properties of Foamed Concrete with Polypropylene Fibres", International Journal of Engineering \& Technology, vol. 7 , no. 3.7 , pp. $411-413,2018$.

[15] Jhatial A.A., Inn G.W., Mohamad N., Alengaram U.J., Mo K.H. and Abdullah R., "Influence of polypropylene fibres on the tensile strength and thermal properties of various densities of foamed concrete", IOP Conference Series: Materials Science and Engineering, 271, No. 1, pp. 1-7, 2017.

[16] EN 197-1:2011. Cement - Part 1: Composition, specifications and conformity criteria for common cements. British Standards Institution, London.

[17] BS EN 12390-3:2019. Testing hardened concrete. Compressive strength of test specimens. British Standards Institution, London.

[18] BS EN 12390-5:2019. Testing hardened concrete. Flexural strength of test specimens.British Standards Institution, London.

[19] ASTM C143 / C143M - 15a Standard Test Method for Slump of Hydraulic Cement Concrete.

[20] Phulpoto, K. B., Jhatial, A. A., Memon, M. J., Sandhu, A. R., and Sohu, S., "Effect of Polypropylene Fibre on the Strength of Concrete Incorporating Rice Husk Ash", Journal of Applied Engineering Sciences, vol. 10, no. 1, 69$71,2020$.

[21] Zhang, M. and Li, H., "Pore structure and chloride permeability of concrete containing nano-particles for pavement", Construction and Building Materials, vol. 25, no. 2, pp. 608 $-616,2011$.

[22] Hadipramana, J., et. al., "Influence of Polypropylene Fiber in Strength of Foamed Concrete",Advanced Materials Research, $488-489$, pp. $253-257,2012$.

[23] Jhatial, A. A., Goh, W. I., Mohamad, N., Mo, K. H. and Sohu, S., "Incorporation of palm oil fuel ash and egg shell powder as supplementary cementitious materials in sustainable foamed concrete", Tehnički vjesnik, vol. 27, no. 5, pp. $1394-1402,2020$.

[24] Mangi, S. A., Ibrahim, M. H. W., "Recycling of Coal Ash in Concrete as a Partial Cementitious Resource", Resources, vol. 8, no. 2, pp. 99, 2019. 